\title{
Reconsiderando a política de colonização no Brasil Imperial: os anos da Regência e o mundo externo
}

Reconsidering Colonization Policy in Imperial Brazil: The Regency Years and the World Beyond ${ }^{1}$

José Juan Pérez Meléndez

Tradução: Luís M. Sander

\section{Resumo}

A colonização não é comumente associada com o período da Regência na história do Brasil Imperial. Durante muito tempo, os historiadores pensavam que, na tumultuada década de 1830, os empreendimentos de colonização diminuíram, em grande parte, por causa da suspensão do financiamento governamental em 1830. Usando documentação primária de diversos arquivos, $\mathrm{o}$ artigo demonstra que os anos da Regência foram, de fato, cruciais para o desenvolvimento da atividade de colonização no Brasil. Como uma época de muita experimentação política, a Regência estabeleceu um projeto de como a colonização seria administrada nas décadas seguintes, sancionando políticas promocionais e favorecendo empresas privadas como os veículos ideais para executá-lo. Mas essas decisões não eram um mero reflexo da vontade soberana das elites políticas no Brasil pós-independência, pois processos e acontecimentos externos no mundo atlântico moldaram diretamente o desenvolvimento da dinâmica da colonização.

Palavras-chave: colonização; imigração; Regência.

\section{Abstract}

Colonization is not commonly associated with the Regency period in the history of Imperial Brazil. Historians have long thought that in the tumultuous 1830 s colonization endeavors subsided, in large part due to the suspension of government funding in 1830. Using primary documentation from diverse archives, this article demonstrates that the Regency years were in fact crucial for the development of the business of colonization in Brazil. As a time of much political experimentation, the Regency established a blueprint for how colonization would be administered in the following decades, enacting promotional policies and favoring private companies as the ideal vehicles to carry it out. But these decisions were not simply a reflection of the sovereign will of political elites in post-independence Brazil, as foreign processes and events in the Atlantic world directly shaped the development of colonization dynamics.

Keywords: colonization; immigration; Regency.

\footnotetext{
* Doutorando em História, Universidade de Chicago. jjperdez@uchicago.edu
} 
A colonização era um elemento sempre presente na vida política do Brasil Imperial (1822-1889). Com força especial nas décadas imediatamente posteriores à independência, migrações planejadas desempenharam papel importante no sentido de permitir que as elites políticas definissem uma série de áreas de políticas consideradas essenciais para a consolidação da soberania nacional, a preservação da integridade territorial e a organização dos mercados interno e de exportação. A colonização, como geralmente se designava o planejamento e a execução de migrações "livres", era um processo versátil, envolvendo o transporte e o assentamento de uma série de diferentes populações, desde grupos indígenas ou degredados até militares de baixa patente e migrantes estrangeiros. Muito antes de 1819, quando João VI estabeleceu Nova Friburgo, uma das mais conhecidas colônias patrocinadas pela realeza no Reino do Brasil, a colonização havia sido empregada pelo governo colonial português. No período das reformas pombalinas, famílias açorianas já haviam sido trazidas para as capitanias meridionais a fim de promover o crescimento populacional. Nas regiões setentrionais do Brasil, duas empresas comerciais construíram a base para o que mais tarde se tornaria uma vigorosa economia extrativa dependente do emprego agressivo de mão de obra indígena flutuante e, mais uma vez, da colonização açoriana.

Essas práticas do antigo regime não deveriam parecer demasiadamente anacrônicas, pois impulsos colonizadores de diferentes tipos, mas especialmente aqueles executados por empresas privadas, persistiram ao longo do século XX. Com o início das migrações em massa na década de 1880, as companhias de colonização se multiplicaram, uma vez que foram chamadas a apoiar e incentivar iniciativas governamentais de recepção de imigrantes. Companhias privadas de colonização mantiveram suas atividades nos estados meridionais do Brasil inclusive nas décadas seguintes a essas migrações, quando o número de imigrantes diminuiu de forma significativa. Durante e depois da Segunda Guerra Mundial, a marcha da colonização prosseguiu de modo confiante com a Expedição Roncador-Xingu, utopia militarista levada a cabo por uma empresa semiprivada que ofereceu aos brasileiros a última repetição do tropo secular da "abertura" do interior do Brasil. Até os dias de hoje, aliás, o Ministério da Justiça mantém "colônias penais agrícolas", e o Instituto Nacional de Colonização e Reforma Agrária (Incra) segue dividindo regiões rurais ou semirrurais em assentamentos. Em geral, as incidências repetidas de colonização ao longo do tempo apresentam uma consistência notável na maneira em que o assentamento planejado de pessoas e a administração que acompanhava esses esforços conformaram diferentes modalidades de poder 
governamental. Mas a reflexão sobre a relação entre o Estado brasileiro e as políticas de colonização no longo prazo não aborda adequadamente as questões de quando e como ideias e projetos de colonização impactaram o desenvolvimento das capacidades "tutelares" ou "infraestruturais" do governo nacional. $^{2}$

O fato de o Império brasileiro se encontrar no ponto médio desse arco de 200 anos no desenvolvimento do conceito e da prática da colonização é bastante significativo. Mas esse dificilmente é o caso de acordo com a historiografia do Brasil Imperial, que evitou sistematicamente um exame aprofundado do fenômeno. Uma das razões para isso é que, seguindo o trabalho de pesquisadores da "Escola de São Paulo", o tema da colonização permaneceu firmemente inserido em uma historiografia mais ampla da escravidão e em interpretações marxistas do período imperial. Consequentemente, crê-se em geral que a colonização existiu em relação direta com a ameaça da abolição, e assim se diz que os planos de colonização ganharam impulso à medida que a escravidão sofria ataques crescentes. Essa perspectiva considerou equivocadamente figuras como "o admirável Vergueiro" - como Sérgio Buarque chamou esse conhecido liberal -, os pioneiros da colonização no Brasil (Costa, 2010; Holanda, 1980).

Essa concepção, porém, define a colonização em termos bastante estreitos como um esforço liderado por liberais que visava exclusivamente promover a imigração europeia branca na segunda metade do século XIX. De certo modo, ela não só negligencia facetas importantes na formação do Brasil Imperial, mas também representa de modo equivocado a história da colonização, que é fenômeno de escopo verdadeiramente global e não pode ser facilmente compreendido mediante explicações estruturalistas. Embora estudos recentes do período imperial tenham afrouxado a rigidez teórica da pesquisa marxista anterior, houve pouco progresso no sentido de criar uma nova compreensão da dinâmica da colonização, especialmente quanto à distribuição do poder político e econômico ao longo da cadeia de suprimento de imigrantes que ligava o Brasil a outros cenários internacionais. A razão por que novas abordagens não conseguiram propor algo novo neste e em outros aspectos é que simplesmente trocaram Marx por Gramsci. Na historiografia recente, a colonização e suas dimensões políticas permaneceriam encerradas na noção de que donos de escravos do Vale do Paraíba fluminense estavam atrás do leme do Estado. Sem dúvida, essa noção tem peso considerável ao demonstrar como a construção doutrinária cumulativa de plataformas e instituições de políticas públicas no Império ocorreu nas mãos de uma forte clique conservadora que se tornou conhecida como os Saquaremas, entre os quais era comum a posse em larga escala de escravos. Mas, na verdade, 
mesmo que esta história tenha sido rigorosa e convincentemente contada por Jeffrey Needell, Ricardo Salles e Tâmis Parron, a ascensão e a queda consequente do poder conservador pouco explicam a construção externa da política interna e do desenvolvimento governamental (Needell, 2006; Salles, 2008; Parron, 2011). Ou seja, à parte de conhecidos momentos de crise internacional (Bill Aberdeen, Questão Christie), os fatores externos têm pouco peso no desenvolvimento de marcos jurídicos e políticos nacionais. Consequentemente, interesses políticos e comerciais profundamente moldados por forças internacionais permanecem inexplicados. Nesse sentido, a colonização pode lançar alguma luz sobre a relação entre processos ou acontecimentos ultramarinos e o desenvolvimento político no Brasil durante as décadas pós-independência. Para mostrar como isso acontece, é necessário recuar e reexaminar os significados e o funcionamento dos projetos de colonização antes de terem interessado a fazendeiros de diferentes matizes.

Foi só no período de consolidação nacional (1850-1865) e da relativa estabilidade política dos anos de conciliação entre os partidos que os fazendeiros das províncias do Rio de Janeiro, Minas Gerais e São Paulo realmente assumiram a causa da colonização. Até então, eles estavam simplesmente fazendo uso de um construto ideológico elaborado muito tempo antes por uma robusta tradição de produção de panfletos e textos no Brasil, e essa tradição era profundamente moldada pela economia política inglesa e escocesa. Até o Primeiro Império, as justificativas para a formulação de uma política nacional de colonização, muitas vezes vinculadas ao problema da distribuição de propriedade e terra, tinham incluído noções do antigo regime sobre povoamento, doutrinas fisiocráticas antigas que tratavam da ocupação efetiva, e defesa geopolítica, especialmente em relação à tumultuada Província Cisplatina no sul do Império. Porém, quando Pedro II subiu ao trono em 1840, a maneira como a colonização era discutida e aplicada no Brasil Imperial havia mudado drasticamente. A colonização, exaltada como uma panaceia para todos os problemas nacionais, tornou-se incrivelmente popular entre legisladores e ministros durante a Regência. Entre os muitos preceitos da colonização, a crença de que empresas privadas especializadas, e não o governo, eram o melhor veículo para a realização dos planos de colonização angariou um número particularmente grande de seguidores naqueles anos tão cruciais para a formação do governo. E, mesmo diante dos muitos fracassos futuros dessas empresas, esse princípio se mostraria durável.

Este artigo abordará os significados da colonização no Brasil Imperial durante o período da Regência que se seguiu à abdicação de Pedro I. A década 
de 1830 e o início da de 1840 presenciaram um ímpeto crescente no sentido de erigir as regulamentações e instituições que posteriormente definiriam a política imperial. A colonização fazia parte desse crescimento inédito em iniciativas de construção institucional, mas um exame atento sugere que os numerosos esforços para promover a imigração, administrar assentamentos diversificados e apoiar empreendimentos privados especializados em projetos coloniais não derivavam de uma concepção consistente de boa governança. Pelo contrário, a série de leis, regulamentações e contratos relacionados à colonização aprovados ao longo da Regência era o reflexo dos trancos e barrancos de um processo de definição de políticas que ainda reagia, em grande parte, a acontecimentos externos e crises imprevistas. Em outras palavras, as medidas tomadas pelos políticos ou homens de Estado durante a Regência para planejar algo semelhante a uma "política de colonização" coerente eram mais do que um simples eco das prerrogativas soberanas das elites políticas: eram suas respostas a situações internas que surgiram em razão de fenômenos internacionais que estavam além do controle dessas elites, como, por exemplo, a Guerra Civil portuguesa, a abolição da escravatura em territórios britânicos e a consolidação do Zollverein, que forçou a migração dos reinos alemães. A despeito de seu caráter contingente, muitas dessas políticas possuíam um extraordinário poder de resistência. É adequado sublinhar que as políticas da Regência sobre naturalização, imigração e o transporte de populações trabalhadoras teriam um efeito duradouro sobre a maneira como governos brasileiros administravam planos de colonização e negociavam com empresas de colonização privadas até bem depois do fim do Império.

\section{A REgÊNCIA E O MUNDO INTERNo}

As discussões públicas sobre planos de colonização não começaram muito bem na Regência. Na ausência de quaisquer leis que prescrevessem como processar propostas de colonização, não havia concordância entre os homens de Estado brasileiros sobre que privilégios deveriam autorizar, se fosse o caso, para esforços migratórios planejados e projetos de assentamento. Com efeito, os projetos de colonização geralmente haviam sido tratados caso a caso. A ineficiência desse procedimento era evidente.

Enquanto propostas iniciadas no Primeiro Reinado (1822-1831) continuavam a ir e vir durante a Regência, novos projetos foram rejeitados pelo fato de não existir uma lei que regulamentasse a doação de sesmarias, cuja concessão havia sido suspensa em $1822 .{ }^{3}$ Para muitos, uma proposta regional como 
essa, a falta de uma política nacional para a distribuição de terras públicas e outros privilégios constituíam um retrocesso insuperável. Tentativas anteriores de estabelecer um modelo nacional para a colonização tinham se perdido em meio à transição para a Regência. Em 1825, o ministro do Tesouro Felisberto Caldeira Brant Pontes, Visconde de Barbacena, tinha convocado uma comissão para esboçar uma política de colonização para todo o Império, mas, apesar de suas boas intenções, quando o relatório da comissão foi publicado em 1827, seu impacto sobre a definição de políticas foi extremamente limitado. Um dos motivos foi que as sugestões da comissão não eram unânimes: o monsenhor Pedro Machado de Miranda Malheiro, administrador financeiro da colônia de Nova Friburgo, retirou seu apoio ao plano tendente ao povoamento redigido pelos outros membros - João Antonio Rodrigues de Carvalho, Manuel José de Souza França e Januário da Cunha Barbosa. ${ }^{4}$ Além disso, protelações costumeiras travavam a audiência do plano no Senado: a Comissão sobre Catequese Indígena, Estatística e Colonização afirmava necessitar de mais informações antes de apresentar seu parecer sobre essa proposta de colonização, a primeira que abrangia todo o Império. ${ }^{5}$

Em contraposição ao Senado, o Poder Executivo agiu de modo mais decidido quanto a questões de colonização, mas também de modo mais opaco. Tanto em 1829 quanto em 1830, a "Fala do trono" deu a Pedro I uma plataforma para urgir os legisladores no sentido de promover a colonização agrária, especialmente em vista da iminente proibição do comércio de escravos. Mas o respaldo do imperador a planos para o assentamento agrário de estrangeiros ocultava os usos militares anteriores - e talvez persistentes - da colonização. Embora a contratação de tropas estrangeiras pelo imperador tivesse sido contestada por causa das revoltas de soldados alemães e irlandeses no Rio de Janeiro em junho de 1828, no ano seguinte Pedro I estava novamente procurando recrutar soldados estrangeiros. Desta vez, porém, tinha-se em vista súditos portugueses, e o processo de recrutamento foi bastante discreto, até que jornais londrinos noticiaram que Pedro I estava organizando um exército de emigrados da Guerra Civil Portuguesa (1828-1834). ${ }^{6}$ Os homens de Estado brasileiros ficavam cada vez mais desconfiados em relação à colonização com soldados estrangeiros na medida em que o Primeiro Império (1822-31) chegava ao fim, ${ }^{7}$ pois eles sabiam que isso significava o envolvimento de Pedro I nas intrigas da família Bragança e, assim, a possibilidade ameaçadora de uma nova união do Brasil com Portugal.

Essa ameaça não cessou completamente com a abdicação de Pedro I. Mesmo depois de 1831, via-se uma série de ministros e legisladores no Brasil 
incentivando uma escalada militar não só para ajudar Maria da Glória a recuperar o trono português, mas também para a restauração de Pedro I. Embora seja difícil provar essas acusações, elas eram extremamente plausíveis. Em 1830, Miguel Calmon Du Pin e Almeida, o então ministro da Fazenda, esclareceu aos deputados na Assembleia Nacional que o imperador lhes tinha aconselhado ajudar os emigrados por razões puramente filantrópicas, e tinha oferecido soldados portugueses a Maria da Glória simplesmente porque, como brasileira, ela requereu essa proteção. Nesse sentido, afirmou ele, Pedro I não agira diferentemente da Grã-Bretanha, França e outras nações que tinham auxiliado a causa dela. ${ }^{8}$ Isso ficaria como exemplo de diplomacia ministerial adequada se não fosse pelo fato de que, ao mesmo tempo, Calmon, monarquista fiel, também estava defendendo o estabelecimento de monarquias em toda a América Latina, se bem que secretamente. ${ }^{9}$

É nesse contexto que numerosas leis e decretos sancionados durante a Regência podem ser reinterpretados como medidas que representavam algo mais do que degraus em uma progressiva elaboração cumulativa de uma política geral para a imigração e colonização. Na verdade, as medidas legais funcionavam como ferramentas estratégicas para lidar com problemas contingentes, muitas vezes imprevistos. Elas também serviam como medidas de precaução para evitar a repetição de problemas passados, como, por exemplo, as desordens de 1828. No entanto, as leis dificilmente serviam a uma única finalidade. Cada lei tinha aplicações diversificadas e podia, naturalmente, ser usada de maneira instrumental. Por exemplo, a lei de naturalização de 1832 parece ser simplesmente uma medida visando à assimilação de imigrantes assentados. Como observou Marcos Justo Tramontini, além de resolver uma questão procedimental básica da forma de organizar a nacionalização de estrangeiros residentes, a lei de naturalização tinha, pelo menos, duas outras aplicações: 1) no contexto local de São Leopoldo, uma florescente colônia fundada em 1824 no Rio Grande do Sul, ela garantia o fornecimento de soldados para a Guarda Nacional, estabelecida em 1831; e 2) ela também inclinava a balança das eleições, uma vez que os colonos naturalizados teriam acesso à política eleitoral, especialmente a funções locais como a de juiz de paz, que era uma instituição consideravelmente poderosa antes de 1840 (Tramontini, 2003, p.199-201). Esse autor quase chega ao ponto de indicar que a naturalização também era uma maneira de intervir em um processo contratual entre o governo e os colonos que pendia fortemente em favor do primeiro, e, assim, poderia provocar protestos diplomáticos por parte dos países natais desses imigrantes, ou seja, de aliados internacionais em potencial. Assim, a 
naturalização oferecia um meio de evitar intervenções de representantes e reclamações de países estrangeiros, especialmente na administração de tropas estrangeiras desmobilizadas como aquelas que se haviam revoltado em 1828. Era também uma maneira de reter os imigrantes como súditos brasileiros, limitando a possibilidade de migrações circulares, que não eram incomuns no caso de súditos portugueses. Aprovada no calor da guerra miguelista, a lei de naturalização brasileira de 1832 poderia sufocar, pelo menos em teoria, a questão contenciosa que estorvara os últimos anos do governo de Pedro I e continuava a ser denunciada no Brasil: uma temida invasão de tropas estrangeiras que reunificariam o Império lusófono. ${ }^{10}$

As múltiplas aplicações da lei de naturalização de 1832, contudo, não deveriam desviar a atenção do fato de que, no início da Regência, persistiam ideias do antigo regime sobre a colonização. Quando se iniciou a discussão de protocolos para a naturalização de estrangeiros na Assembleia Nacional em 1826, Nicolau Vergueiro, um político nascido em Portugal que se tornaria o mais conhecido empresário da colonização em 1850, era taxativo quanto à primazia de povoar o interior do Brasil com colonos nacionais e não estrangeiros. Sete anos mais tarde, como ministro do Império, sua concepção permanecia a mesma: “A colonização estrangeira por conta do Governo”, afirmou Vergueiro,

he pouco propria [na medida em que é] excessivamente dispendiosa: seria porem de huma utilidade incalculavel estabelecer Colonias de Nacionaes em lugares ermos ... Estas Colonias, compondo-se de indigentes, e de réos condemnados a trabalho, ou degredo, alem de augmentarem as producções agrarias, concorrerião a franquear a comunicação entre povoações remotas ... e suppririão ... a falta de Casas de Correcção... ${ }^{11}$

Em 1836, porém, ele, com seus cunhados da família Faro, estava entre os principais acionistas da Sociedade Promotora da Colonisação [sic], a primeira empresa brasileira de colonização especializada no recrutamento e importação de trabalhadores estrangeiros, especialmente açorianos, para o Brasil. O que tinha mudado?

A mudança radical de Vergueiro fazia parte de uma transformação maior nos significados da colonização, cujo centro era, por um lado, a aprovação do Ato Adicional, que inaugurou legislativos provinciais no Brasil, e, por outro, a morte do duque de Bragança, anteriormente Pedro I, em 1834. Desaparecidas a ameaça da restauração mediante um exército de colonos portugueses, 
irlandeses e poloneses e a sombra ameaçadora do absolutismo, a política e os negócios ganharam forte impulso no Brasil. Práticas sociais anteriormente banidas, como a maçonaria, foram relançadas, e novos níveis de atividade política se abriram graças às reformas liberais de 1834. É a essa súbita e frenética socialização que as elites brasileiras se referiam quando começaram a invocar um "espírito de associação" para justificar parcerias comerciais e atividades filantrópicas, entre as quais projetos de colonização ocupavam um lugar de destaque. É verdade que alusões ao espírito de associação tinham precedido a morte de Pedro I, como fica evidente na edição de 1833 de O Auxiliador da Indústria Nacional, que publicou o texto de um discurso proferido publicamente por José Silvestre Rebello intitulado "Memória sobre a necessidade de se crearem sociedades entre os homens". Mas somente depois de 1834 houve um apelo mais urgente para cultivar esse espírito. Como escreveu Miguel Calmon, na época um proeminente político baiano, em seu tratado de 1835 sobre a colonização, intitulado Memória sobre o estabelecimento d'uma Companhia de colonisação nesta Provincia, a ausência do espírito de associação era uma das principais razões pelas quais a colonização não havia sido bemsucedida no Brasil. Considerando que o governo brasileiro ainda estava lutando para consolidar sua "administração pública", a solução, em sua opinião, era "a reunião de nossas faculdades intelectuaes e pecuniarias, isto he, uma Companhia bem organizada poderá afrontar ousadamente alguns perigos, vencer muitas dificuldades, e fazer ao Paiz, com a introdução de braços livres ... Nenhum objecto ha por tanto digno do espírito de associação ... do que o da Colonisação Estrangeira, e mesmo da Nacional com o andar dos tempos..." (Rebello, 1833; Almeida, 1835, p.12).

Para compreender essa transformação, é importante colocar de lado a alegação generalizada de que os esforços de colonização foram oficialmente suspensos depois da supressão de verbas provinciais para a colonização na lei orçamentária de 15 de dezembro de $1830 .{ }^{12}$ Ao contrário do que historiadores vêm sustentando durante muito tempo, os empreendimentos de colonização continuaram sob diferentes formas ao longo da primeira metade da Regência. Em estudo recente a respeito do papel do governo central dos Estados Unidos na promoção do desenvolvimento da infraestrutura durante o século XIX, Brian Balogh sustentou que alocações orçamentárias, e não intervenções federais diretas em assuntos locais, constituíram os meios mais eficazes para a ação governamental. Nesse sentido, pode-se observar mais facilmente a concepção de desenvolvimento do governo central em sua destinação de recursos para determinados projetos - como a construção de estradas ou verbas para 
Tabela 1 - Alocações orçamentárias para itens relacionados à colonização, 1831-1845

\begin{tabular}{|c|c|c|c|c|}
\hline Ano & $\begin{array}{c}\text { Item } \\
\text { orçamentário }\end{array}$ & $\begin{array}{l}\text { Quantia } \\
\text { destinada } \\
\text { (mil-réis) }\end{array}$ & $\begin{array}{c}\text { Alocação total ao } \\
\text { respectivo Ministério: } \\
\text { Império }(\mathrm{I}), \\
\text { Fazenda }(\mathrm{F}), \\
\text { Justiça }(\mathrm{J}), \\
\text { Marinha }(\mathrm{M})\end{array}$ & $\begin{array}{l}\text { Proporção dos } \\
\text { gastos dos } \\
\text { Ministérios } \\
\text { para a } \\
\text { colonização (\%) }\end{array}$ \\
\hline $1831-32$ & $\begin{array}{l}\text { "Catequese" indígena, } \\
\text { verbas para províncias }\end{array}$ & $18: 266 \$ 600$ & $1.438: 142 \$ 754(\mathrm{I})$ & 1,3 \\
\hline \multirow[b]{2}{*}{$1833-34$} & $\begin{array}{l}\text { Colônias para degredados } \\
\text { e vagabundos }\end{array}$ & $50: 000 \$ 000$ & 434:004\$000 (J) & 11,5 \\
\hline & $\begin{array}{l}\text { Censo para RG, } \\
\text { gratificação para } \\
\text { agrimensor de colonos }\end{array}$ & $3: 400 \$ 000$ & $5.247: 197 \$ 000(\mathrm{~F})$ & 0,06 \\
\hline \multirow{3}{*}{$1834-35$} & Colônias para degredados & $\begin{array}{l}50: 000 \$ 000 \\
52: 000 \$ 000\end{array}$ & $434: 604 \$ 900(\mathrm{~J})$ & 11,5 \\
\hline & $\begin{array}{l}\text { "Catequese" indígena, } \\
\text { verbas para províncias }\end{array}$ & --- & \multirow{2}{*}{$2.855: 507 \$ 000(\mathrm{~F})$} & \multirow{2}{*}{1,9} \\
\hline & $\begin{array}{l}\text { Censo para RG, } \\
\text { gratificação para } \\
\text { agrimensor dos colonos }\end{array}$ & $3: 400 \$ 000$ & & \\
\hline \multirow[b]{2}{*}{$1835-36$} & $\begin{array}{l}\text { Verbas para colônias } \\
\text { de degradados }\end{array}$ & $12: 000 \$ 000$ & {$[434: 604 \$ 900](\mathrm{J})$} & 2,8 \\
\hline & $\begin{array}{l}\text { "Catequese" indígena, } \\
\text { verbas para províncias } \\
\text { Censo para RG e medição } \\
\text { de terras para colonos }\end{array}$ & $\begin{array}{l}52: 000 \$ 000 \\
3: 400 \$ 000\end{array}$ & $2.855: 507 \$ 000(\mathrm{~F})$ & 1,9 \\
\hline $1836-37$ & $\begin{array}{l}\text { Colônias para degredados } \\
\text { e vagabundos }\end{array}$ & $12: 000 \$ 000$ & 696:794\$000 (J) & 1,7 \\
\hline $1837-38$ & Nenhum & --- & --- & --- \\
\hline $1838-39$ & Nenhum & --- & --- & --- \\
\hline
\end{tabular}




\begin{tabular}{|c|c|c|c|c|}
\hline $1839-40$ & Nenhum & --- & --- & --- \\
\hline $1840-41$ & Nenhum & --- & --- & --- \\
\hline $1841-42$ & Nenhum & --- & --- & --- \\
\hline \multirow{2}{*}{$1842-43$} & $\begin{array}{l}\text { Contrato de colonização: } \\
\text { província SC \& Dr. Mure }\end{array}$ & $64: 000 \$ 000$ & $2.535: 791 \$ 800(\mathrm{I})$ & 2,5 \\
\hline & Recrutamento no exterior & $30: 000 \$ 000$ & 2.618:296\$966 (M) & --- \\
\hline \multirow[t]{2}{*}{$1843-44$} & $\begin{array}{l}\text { "Catequese" e } \\
\text { "civilização" indígena }\end{array}$ & $16: 000 \$ 000$ & \multirow[t]{2}{*}{$2.644: 544 \$ 000(\mathrm{I})$} & \multirow[t]{2}{*}{1} \\
\hline & Colonização & $10: 000 \$ 000$ & & \\
\hline \multirow{2}{*}{$1844-45$} & $\begin{array}{l}\text { "Catequese" e } \\
\text { "civilização" indígena }\end{array}$ & $16: 000 \$ 000$ & \multirow[t]{2}{*}{$2.644: 544 \$ 000(\mathrm{I})$} & \multirow[t]{2}{*}{1} \\
\hline & Colonização & $10: 000 \$ 000$ & & \\
\hline
\end{tabular}

Fontes: Liberato de Castro Carreira, História financeira e orçamentária do Império do Brasil, t. I, Brasília: Senado Federal, 1980, p.188, 190-193, 233, 236; Anais do Senado, t. III (1833). RJ: 1916, p.47; Lei de 24 de Outubro de 1832, in: Coleção de Leis do Império do Brasil (CLIB) (1832); Lei n 58, de 8 de Outubro de 1833, CLIB (1833); Lei no 38, de 3 de Outubro de 1834, CLIB (1834); Lei $\mathrm{n}^{\circ}$ 99, de 31 de Outubro de 1835, CLIB (1835); Lei no 70, de 22 de Outubro de 1836, CLIB (1836), t. XI. RJ: Typ. de J. Villeneuve, 1937, p.127-134; Lei no 106 de 11 de Outubro de 1837, CLIB (1837), RJ: Typ. Nacional, 1861, p.66-75; Lei no 60 de 20 de Outubro de 1838. CLIB (1838); Lei ${ }^{\circ} 243$ de 30 de Novembro de 1841, CLIB (1841); Lei no 317, de 21 de Outubro de 1843, CLIB (1843) t, V. RJ: Typ. Nacional, 1944, p.59-80. A menos que haja outra indicação, parte da legislação foi consultada pela máquina de busca "Legislação" da Câmara dos Deputados, disponível em: www2.camara.leg.br; Acesso em: $1^{\circ}$ jan.-1º ago. 2014.

agrimensores - do que em sua capacidade de forçar governos estaduais ou municipais a cumprirem ordens federais. De modo semelhante, seria possível reconstituir qual era a concepção de colonização do governo brasileiro durante os anos da Regência mediante exame atento de alocações orçamentárias destinadas a atividades de colonização tão diversas quanto a "catequese" indígena, que implicava a concentração de índios em aldeias, ou colônias penais (ver Tabela 1). O financiamento de tais empreendimentos continuou bem além da suspensão de verbas provinciais para a colonização em 1830, mas essas atividades não definiram uma política geral de qualquer espécie. As despesas orçamentárias destinadas para atividades relacionadas à colonização, isto é, a qualquer empreendimento que implicava o transporte e o assentamento produtivo de uma dada população, eram bastante diversificadas nos seis primeiros anos 
da Regência, variando na quantidade de recursos alocados e nos ministérios aos quais essas verbas eram destinadas, incluindo os do Império, da Justiça e da Fazenda. A maioria das alocações é consistente com os fundos destinados para atividades de colonização nos anos pós-Regência. Aquelas que não o são - como os recursos previstos para colônias de degredo, que subiram para $11 \%$ do total do orçamento do Ministério da Justiça em 1833-1834 e 1834-1835 podem ser explicadas plausivelmente salientando que Aureliano de Souza e Oliveira Coutinho, futuro Visconde de Sepetiba, esteve à frente desse ministério durante esses anos. Aureliano, que em 1847 seria denunciado como líder de uma facção áulica, também era uma das figuras mais envolvidas em projetos de colonização no início do Segundo Império, especialmente na fundação da colônia imperial de Petrópolis (1845). O orçamento do Ministério da Justiça para esses anos indica que Aureliano estava interessado em projetos de colonização desde cedo. Considerando, porém, que as verbas para degredos foram drasticamente reduzidas quando ele deixou o Ministério da Justiça em 1835, faz sentido enfatizar o quanto a obtenção de recursos destinados para empreendimentos de colonização dependia da posição e graduação de seus promotores. ${ }^{13}$

Existe ainda outra anomalia que salta aos olhos nas alocações orçamentárias durante a Regência. É difícil ignorar o fato de que, a despeito dos diversos tipos de colonização financiados nos primeiros anos da Regência, os orçamentos de 1837-1838 até 1841-1842 não destinavam quaisquer recursos para projetos de colonização. A razão foi que, em 1836, a Sociedade Promotora da Colonisação tinha sido fundada na Corte, e uma associação coirmã, a Sociedade Colonisadora da Bahia, em Salvador. ${ }^{14}$ No momento em que as primeiras empresas de colonização organizadas no Brasil iniciaram suas atividades, o financiamento governamental para atividades relacionadas com a colonização secou, como se a máxima sugerida por Calmon, que presidia a empresa baiana, tivesse se cumprido: o governo deveria se concentrar na administração pública e deixar companhias privadas fazerem o trabalho da colonização.

Enquanto a lista de membros da Sociedade Colonisadora da Bahia tinha um caráter mais provincial, a Sociedade Promotora na Corte reunia uma miscelânea de eminentes famílias fluminenses (Nogueira da Gama, Gonçalves de Morais, Souza Breves), políticos importantes de outras províncias, como o Marquês de Barbacena e Francisco Gê de Acayaba de Montezuma, diplomatas do nível de Luiz de Menezes Vasconcellos Drummond, e comerciantes como Francisco da Paula Veloso, que possuía uma casa de câmbio, e Jorge Naylor. Também é importante mencionar a presença de acionistas portugueses e de 
brasileiros envolvidos com a maçonaria, pois essas conexões portuguesas e maçônicas parecem ter expandido consideravelmente $\mathrm{o}$ alcance associativo de ambas as sociedades colonizadoras. No entanto, apesar da incrível diversidade entre os membros dessas empresas em termos de profissão, proveniência e status, o verdadeiro sucesso desses empreendimentos estava vinculado aos padrinhos políticos que escolheram. A empresa baiana sem dúvida escolhera bem ao colocar Calmon na presidência, pois a essa altura ele era um político de peso, respeitado e experiente. A Sociedade Promotora também agiu astutamente ao escolher Pedro de Araújo Lima como seu primeiro presidente, pouco antes de ele ser escolhido para ser regente por Diogo Feijó. Essa talvez tenha sido a razão pela qual, em 1838, outro pernambucano importante, Antônio Francisco de Paula de Holanda e Cavalcanti, aparecia como presidente da Sociedade Promotora. ${ }^{15}$ Embora Araújo Lima e Holanda e Cavalcanti fossem - teoricamente - de campos ideológicos opostos, tinham algo em comum: eram astros políticos ascendentes com conexões incrivelmente boas (em 1838, Holanda e Cavalcanti seria nomeado senador).

A eleição de líderes políticos proeminentes e promissores era a maneira dessas empresas tirarem o maior proveito do desenvolvimento institucional que se acumulara durante a Regência. A abertura política acontecida a partir de 1834 havia indubitavelmente facilitado o trabalho desses empreendimentos de colonização em muitos níveis novos. A abolição das alocações de recursos de colonização para governos provinciais, determinada pela lei orçamentária de 1830 e reiterada pelo decreto de 12 de abril de 1835, tinha consolidado o controle das verbas para colonização por parte do governo central, mas não havia reduzido a capacidade das províncias, formulada no Ato Adicional de 1834, de manter contratos com empresas privadas de navegação e mineração cujos estatutos frequentemente previam o estabelecimento de colônias. A partir de 1834, projetos de colonização que estavam à espera viram uma janela de oportunidade no contexto político expandido e nas maiores chances de patrocínio. Isso se prolongaria até o Segundo Império, pois a conservadora "Lei Interpretativa" (Lei no 105, 12 de maio de 1840) que revisou o Ato Adicional deixou intacta essa capacidade das Assembleias Legislativas. De forma crescente, mais níveis de governo eram chamados a desempenhar um papel ativo na promoção da colonização. Com efeito, o Decreto de 9 de dezembro de 1835 determinava que presidentes e assembleias provinciais "promovessem" atividades de colonização dando a atores privados, incluindo os próprios colonos, o apoio de que precisavam. Propostas de colonização por parte de associações ou companhias privadas começaram a chegar ao governo central também por 
meio de Câmaras Municipais, como no caso da Câmara de Ouro Preto, que, em 1835, apoiou a Companhia de Navegação do Rio Doce, que João Diogo Sturz, um súdito da Baviera, tinha se esforçado - arduamente, mas em vão para lançar desde 1832. O fato de a Companhia do Rio Doce ter fechado um contrato com o governo central em 1836, mas ter lutado continuamente por iniciar suas operações, é um reflexo da importância que políticos que exerciam o papel de patronos tinham para o sucesso dessas companhias. ${ }^{16}$ Sturz havia fundado sua companhia na Inglaterra, não no Brasil, e, apesar de seus numerosos esforços para estabelecer alianças com políticos brasileiros, não tivera êxito. Mas o trabalho árduo de Sturz não passou despercebido. Em 1843, depois de naturalizado cidadão brasileiro, ele foi nomeado cônsul geral do Brasil na Prússia, uma posição-chave na promoção da migração para o Brasil nas décadas seguintes. ${ }^{17}$

\section{O MUNDO EXTERNO, A VIAGEM PARA DENTRO}

Com efeito, nos primeiros anos do Segundo Império, Sturz era um dos principais informantes do Império brasileiro sobre o tema da colonização. No início da década de 1840, Sturz enviava regularmente a Januário da Cunha Barbosa, secretário do Instituto Histórico e Geográfico Brasileiro, livros e panfletos que coletava em Berlim e em suas viagens pela Europa, principalmente em Londres. O material enviado por Sturz, que se concentrava nas mais recentes políticas e debates sobre reformas nos reinos britânico e alemão, incluíam os relatórios da Comissão para as Leis dos Pobres de 1835-1845, revistas focadas em florescentes colônias britânicas, como a Fisher's Colonial Magazine e a Colonization Circular, e inúmeros panfletos sobre o sul da Austrália, Nova Zelândia e Canadá, incluindo os prospectos e relatórios das empresas de colonização que vinham operando ali desde a década de 1820. Sturz também enviava material sobre o desenvolvimento da união aduaneira ou Zollverein até 1842, bem como sobre os esforços de empresas como a do sul da Austrália para recrutar emigrantes alemães. Toda essa literatura encontraria eco ao longo do Segundo Império, especialmente no período que antecedeu a Lei de Terras de 1850. Porém, embora estivesse incrivelmente informado quanto à bibliografia existente sobre questões de colonização da época, Sturz não pode ser considerado o pioneiro na transmissão dessas valiosas informações ao governo imperial brasileiro. Sturz simplesmente fazia parte de um corpo diplomático organizado pelo Decreto de 14 de abril de 1834 como parte do desenvolvimento institucional ocorrido durante os anos da Regência. 
Efetivamente, ao longo da década de 1830, textos importantes relativos ao negócio da colonização no mundo britânico e à emigração alemã já haviam alcançado o Rio de Janeiro, Pernambuco e a Bahia como material despachado pela legação brasileira em Paris. À frente dela, depois de 1837, estava José de Araújo Ribeiro, que servira como enviado especial à corte de Maria II e como presidente provincial do Rio Grande do Sul no início da Revolução Farroupilha. Araújo Ribeiro, que mostrou ser um hábil bibliógrafo por seus próprios méritos, despachava livros via Le Havre, que também se tornaria, com o tempo, um importante porto de partida de migrantes que iam para o Brasil. O material que enviou incluía Elements of Political Economy (1821), de James Mill, Illustrations and proofs of the principle of population (1822), de Francis Place, e muitos números da Revue des deux Mondes, além de vários outros periódicos. Dentre eles se destacava a Revue Britannique, que era enviada quase continuamente para a Faculdade de Direito de Olinda, em Pernambuco, a Faculdade de Medicina na Bahia e a biblioteca pública da Corte de 1834 a $1837 .{ }^{18}$ A Revue Britannique se destaca entre outros periódicos semelhantes por oferecer os mais recentes artigos - em tradução francesa - de publicações britânicas relativas à economia política, que incluíam amplos relatos sobre o estado da emigração para colônias ultramarinas e as companhias que as administravam.

Quadro 1 - Títulos de artigos selecionados de números da Revue Britannique enviados ao Brasil, 1836-1837

\begin{tabular}{|l|}
\hline Situation des Colonies anglaises en 1836 \\
\hline Situation des dernières classes en Irlande \\
\hline $\begin{array}{l}\text { État actuel de la colonies des Cygnes, dans la Nouvelle Galles du Sud } \\
\text { (colônia do Swan-River, Austrália) }\end{array}$ \\
\hline Résultats comparés des commerce des bois du Canada et de la Baltique \\
\hline État actuel des deux Canadas \\
\hline Agriculture en Russie \\
\hline Nouvelle colonie formée en Australie \\
\hline
\end{tabular}

Havia também uma considerável recepção de obras britânicas em inglês, o que garantia que as fontes estivessem mais atualizadas do que suas traduções francesas, muitas vezes atrasadas 20 anos em relação a seus originais. A obra Memória de Miguel Calmon, citada anteriormente, é um bom exemplo porque 
começava com uma epígrafe em inglês, que dizia: "The business of settling a new Country is much better managed by private adventurers than by government" [O negócio da colonização de um novo país é muito mais bem administrado por empreendedores privados do que pelo governo]. A citação se originou de um artigo intitulado "On Colonial Undertakings" [Sobre empreendimentos coloniais] publicado no Blackwood's Magazine de Edimburgo, em 1826. O autor, indicado como "Bandana”, não era outro senão John Galt, o hábil administrador da Canada Company e da British American Land Company, as duas mais importantes companhias de colonização do Canadá. Ao fazer referência a Galt, Calmon mostra que as elites brasileiras estavam bem familiarizadas com iniciativas comerciais ultramarinas e bastante atentas ao desempenho de empresas de colonização estabelecidas nas décadas de 1820 e 1830 no Canadá Superior e no Canadá Inferior, no sul da Austrália, na Nova Zelândia e inclusive no Texas, quando este ainda era um território mexicano.

É por meio de conexões como essas que melhor se compreendem as constantes referências à "colonização sistemática" no contexto brasileiro. Era seguindo de perto o que outros países, e suas companhias, estavam fazendo que as elites brasileiras planejavam suas próprias formas de proceder à colonização. Nesse tocante, o contexto britânico era uma referência central pelo fato de as políticas de colonização estarem no centro de discussões políticas do Reino Unido como em nenhum outro lugar. Essas discussões giravam em torno do conceito de "colonização sistemática", que se referia à padronização de processos de recrutamento, transporte e assentamento de migrantes em florescentes colônias ultramarinas. ${ }^{19}$ Contudo, no Brasil pós-independência, a colonização implicava não o envio para colônias ultramarinas, das quais o Brasil não possuía nenhuma, mas o encaminhamento de migrantes para o interior do Império. No caso do Brasil, a desejada sistematização de atividades de colonização referia-se primordialmente à necessidade de estabelecer protocolos jurídicos e administrativos para processar propostas de colonização e cuidar de seu sucesso, especialmente em termos financeiros. Com o tempo, qualquer discussão a respeito de sistematização passaria a incluir outros interesses internos relativos a atividades de colonização. $\mathrm{Na}$ época em que as duas companhias de colonização foram lançadas no Rio e na Bahia, o que estava em jogo era a sistematização da contratação de mão de obra, o que a Lei no 108 de 11 de outubro de 1837 sobre acordos de "locação de serviços" se propôs a fazer.

Está claro que noções "teóricas” derivadas da economia política moldaram compreensões de colonização e imigração no Brasil Imperial, especialmente em termos do valor prático delas de uma perspectiva governamental. Julgando 
com base na aparição consistente de construtos como "colonização sistemática" em relatórios ministeriais e discussões legislativas durante a década de 1840 , é fácil perceber como textos e leituras do exterior se infiltraram no processo de definição de políticas públicas. Mas a formulação de decisões e políticas relacionadas à colonização não tinha a ver apenas com os livros. Longe de qualquer representação mecanicista do processo de definição de políticas, a maioria das leis e decretos que regulamentavam o recrutamento e assentamento de migrantes foi determinada por casualidade durante a Regência. Fluxos de migrantes estavam acontecendo em todo o mundo na primeira metade do século XIX. Considerando isso, e sem tentar suprimir o caráter soberano das prerrogativas dos políticos brasileiros, seria útil reformular suas iniciativas quanto à colonização e imigração como uma reação a forças que estavam realmente além de seu controle. $\mathrm{O}$ que as elites políticas brasileiras podiam fazer e fizeram foi ajustar suas reações a esses fluxos migratórios de modo a restringir a concorrência acirrada - ainda que subestimada - em torno de fluxos de migrantes no mundo atlântico e além dele.

Um dos fluxos migratórios mais robustos para o Brasil na década de 1830, a migração açoriana durante a Guerra Civil portuguesa e depois dela, exemplifica as tensões que surgiram da competitividade entre o Império brasileiro e outras potências no sentido de tirar proveito da migração. Embora esteja bem documentado que os portugueses constituíam os migrantes mais numerosos para o Brasil, ao menos até o começo das migrações em massa de italianos, a documentação necessária para fazer estimativas está, em grande parte, concentrada nas décadas depois de 1850 (Joaquim da Costa Leite, 1987; Klein, 1991, p.316). Ainda assim, apesar da falta ou escassez da documentação, a importância de migrantes portugueses para o Brasil, e para o Rio de Janeiro mais especificamente, é evidente considerando que os estrangeiros livres eram a população que mais rapidamente crescia na Corte de 1838-1849 (Barbosa Nunes, 2000, p.43) e que os portugueses eram o maior grupo dos nascidos no exterior (Leite, 1994; Nunes, 2000).

O fato de a maioria dos migrantes portugueses ter sido identificada pela nacionalidade e não pela região de proveniência no período de 1822-1850 dificulta distinguir um fluxo especificamente açoriano dentro da migração portuguesa mais ampla durante a Regência. Seria possível extrapolar a partir de contagens de imigrantes como aquelas encontradas por Fernandes Alves no Diário do Governo de Portugal para o ano de 1845 para se ter uma noção, retroativamente, de qual pode ter sido a proporção de açorianos em relação à migração portuguesa total: naquele ano, dos 3.355 migrantes portugueses, a 
maioria (1.706) veio do Porto, mas os açorianos eram o segundo maior grupo de emigrantes (1.284). Usando essa proporção, poder-se-ia estimar que dos 1.918 portugueses que, segundo J. D. Sturz, chegaram ao Rio de Janeiro de 1835-1836, aproximadamente 730 poderiam ter sido açorianos. Há indícios suficientes em jornais e relatórios governamentais para sugerir que os açorianos eram os migrantes preferidos para a Sociedade Promotora da Colonisação de 1836, que até março de 1838 tinha cadastrado um total de 2.112 colonos. É impossível determinar quantos desses eram açorianos, embora Luiz Felipe de Alencastro tenha observado que dos 2.421 portugueses que entraram no Rio naquele mesmo ano, 25\% (615 indivíduos) eram de origem açoriana. ${ }^{20}$

O aumento da saída de migrantes do arquipélago açoriano tinha, na verdade, começado durante a Guerra Civil, quando jovens tentavam, aparentemente, evitar o alistamento militar nas forças constitucionalistas. Na época em que se fundou a Sociedade Promotora, já se relatara a chegada ao Rio de numerosos navios com imigrantes açorianos, todos disponíveis para contratação. A própria Memória de Calmon já mencionara que a chegada ao Rio da escuna Fayalense, que carregava açorianos, ofereceu uma "oportunidade para a colonização" que uma companhia podia explorar convenientemente. Nesse sentido, a Sociedade Promotora estava simplesmente tirando proveito de um fluxo migratório já existente. Mas ela passou rapidamente a desenvolver estratégias para atrair açorianos ao Brasil. Em 1838, o administrador geral de Angra do Heroísmo, que estava encarregado de conceder passaportes a imigrantes, queixou-se amargamente ao procurador de Maria II que navios como o Senador Vergueiro estavam aceitando migrantes a bordo e tentando partir sem passaportes e licenças exigidas. ${ }^{21}$ Quando eram impedidas de fazer isso, essas embarcações recebiam autorização para navegar para outras ilhas do arquipélago de Açores ou para o continente português, mas estas eram muitas vezes viagens-fantasma. A migração clandestina se tornou uma preocupação para Portugal durante esses anos, em meio a crescentes acusações contra uma nova "escravidão branca". Essa designação não era inteiramente retórica, pois viagens transatlânticas sob as bandeiras brasileira e portuguesa eram ainda gravemente insalubres na época.

Alegações de maus tratos e condições sanitárias precárias nos navios que transportavam açorianos através do Atlântico conseguiram chamar a atenção da monarca portuguesa. Em 1839, o governo de Maria II começou a oferecer passagens gratuitas para Angola a quaisquer migrantes portugueses carentes no Brasil. Mas havia algo mais do que aquilo que é visível nessa oferta benigna da rainha de Portugal, nascida no Brasil: apenas um ano antes, o Executivo 
português havia lançado oficialmente esforços de colonização em Moçambique, aprovando o estabelecimento da Companhia de Agricultura, Indústria e Commercio, oferecendo diretrizes para o assentamento e até enviando um navio carregado de degredados. ${ }^{22}$ É muito provável que os migrantes açorianos de portos brasileiros que aceitaram as passagens para Angola se destinassem às florescentes colônias portuguesas na África oriental.

Essa competição não declarada para orientar e reorientar movimentos migratórios era moldada pelas necessidades e contingências de um mundo marítimo pré-vapor. Afinal, era mais fácil enviar colonos portugueses diretamente do Rio para Moçambique do que do Atlântico Norte: não só a viagem seria mais curta, mas os ventos do oeste prevalecentes levariam os navios a vela para seu destino muito mais rapidamente. Mas nem tudo era calculado racionalmente. A viagem marítima também implicava muitas contingências que impactavam o resultado de empreendimentos colonizadores de maneira significativa. A capital do Império brasileiro era um importante ponto de passagem para navios que rumavam para muitos destinos no hemisfério Sul: Montevidéu, Buenos Aires, Valparaíso, mas também o Cabo da Boa Esperança, Calcutá, Austrália. Além disso, o Rio era ponto de parada para navios que necessitavam renovar o estoque de água potável ou gêneros alimentícios e consertar vazamentos ameaçadores, particularmente se havia à mão madeiras resistentes ao apodrecimento, especialmente mediante o contrabando de madeira. Isso colocava os políticos brasileiros que defendiam a colonização em uma posição que podiam explorar estrategicamente em relação a movimentos populacionais espontâneos e promovidos por políticas públicas, pois os recursos e a localização geográfica do Rio haviam colocado o Brasil em um ponto crucial das migrações mundiais, e não somente no mundo lusófono. Os primeiros colonos atraídos pela Sociedade Promotora em 1836 eram originários das Ilhas Canárias e tinham sido originalmente contratados para trabalhar no Uruguai.

Mais importantes, porém, eram as migrações orquestradas no mundo britânico, em cujo mapa o Rio de Janeiro figurava como importante parada de descanso e polo comercial. O Rio era um porto de escala preferencial para navios que transportavam emigrantes que estavam a caminho de nascentes colônias de colonizadores ou apenados da Nova Zelândia, Adelaide, Ilha de Van Diemen, Port Phillip e Sydney, entre outras. As estimativas somente para colonos assistidos pelo governo que iam do Reino Unido para a Austrália na década de 1830 são de cerca de 69 mil, um número que devia muito à melhora das condições sanitárias ordenada pelas autoridades britânicas em viagens de 
presidiários com destino à Austrália (Haines; Shlomowitz, 1991, p.52; 2003). Ainda não está claro exatamente quantos desses navios com destino à Oceania aportaram no Rio durante a Regência e o Segundo Império, mas suas paradas ali não eram incomuns. Tampouco eram seus motivos, como mostram os meticulosos "Resultados do comércio britânico" de 1837-1841 preparados por Robert Hesketh, cônsul britânico no Rio. Por exemplo, o Palmia, de 602 toneladas, com destino a Sydney com emigrantes, "aportou para reabastecimento" no Rio, em 14 de junho de 1838, e antes, em 12 de janeiro, o Lord Goderich, com destino ao sul da Austrália, "aportou no Rio em consequência de conflitos a bordo". Em 1839, de 207 navios estrangeiros que deixaram o Rio, pelo menos 25 rumaram para colônias britânicas. Algumas dessas embarcações, aliás, se especializaram em um transporte específico de emigrantes, como o Planter, empregado no transporte de presidiárias para a Austrália. ${ }^{23}$

Além de reabastecer seus suprimentos ou lidar com motins muitas vezes motivados pela fome, esses navios de alta tonelagem (seu peso variava entre 400 e 600 toneladas, em contraste com os navios negreiros ilegais de aproximadamente 200 toneladas) talvez tivessem optado por aportar no Rio para diminuir suas despesas. Em 1836, o governo brasileiro aprovara uma lei que oferecia isenção de taxa de ancoragem para qualquer navio que transportasse mais de cem colonos brancos, outra iniciativa indireta para estimular, e não financiar, esforços de colonização. É necessária mais pesquisa para determinar se e quando esses navios tinham direito a tal isenção. Por enquanto, é suficiente enfatizar que a suspensão de uma importante fonte de receita do Estado como a taxa de ancoragem fazia parte dos esforços das autoridades brasileiras para atrair navios com migrantes, ou suas cargas, para o solo brasileiro. Fazer propostas a colonos que rumavam para outro lugar, mas aportavam no Rio, era prática comum entre funcionários de portos e até mesmo entre políticos brasileiros. Havia acusações periódicas contra o governo brasileiro por tentar convencer colonos que se dirigiam a colônias britânicas a permanecer e, também, por induzi-los a se amotinarem se as conversas com seus capitães não transcorressem tranquilamente. $O$ caso dos alemães que haviam sido contratados para trabalhar na Austrália e tinham deixado o Havre no navio francês Justine é ilustrativo. Depois de sobreviverem com dificuldade a uma tempestade no Atlântico com grandes perdas de animais e suprimento de água, o Justine aportou no Rio no final de novembro de 1837. Enquanto o capitão supervisionava a reposição de suprimentos, um funcionário não identificado do governo brasileiro supostamente lhe ofereceu 20 contos para desembarcar o grupo de colonos alemães e lhes permitir que ficassem para trabalhar no 
Brasil. O capitão do Justine pensou na oferta, mas a recusou para honrar seu contrato de serviço inicial. Supostamente, o governo brasileiro, então, forneceu armas aos alemães, que se recusaram a continuar sua viagem. Confrontado com a ameaça de violência, o capitão acabou aceitando a nova proposta do governo de 12,5 contos. Na primeira semana de dezembro, a Sociedade Promotora da Colonisação estava oferecendo 226 colonos alemães - a maioria deles "cazaes com família ... lavradores de profissão" - a qualquer interessado em empregá-los. O Justine, por sua vez, seguiu viagem para carregar açúcar em Santos, entregá-lo em Valparaíso e chegar a Sydney via Nova Zelândia com um carregamento de trigo, o que exemplifica como os navios migrantes eram adaptáveis para se manter financeiramente. ${ }^{24}$

No caso do Justine, não está claro que relação existia entre o governo imperial e a Sociedade Promotora. O aliciador não identificado do capitão do navio simplesmente era um membro da Sociedade que também era ou tinha sido funcionário do governo? Em todo caso, se for verdade que o governo ofereceu 20 contos, essa situação evidenciaria que recursos extraordinários podiam ser desembolsados para a colonização sem que aparecessem em orçamentos anuais. Além disso, seria uma demonstração do esforço coordenado entre o governo imperial e uma das mais antigas e funcionais empresas privadas de colonização do Brasil. Era efetivamente do maior interesse do governo brasileiro ter certo grau de participação, e de supervisão, no processo de recrutamento de colonos. Fazer isso lhe permitiria "sistematizar" e controlar transações isoladas de colonização que mais tarde poderiam se transformar em situações diplomáticas delicadas. Além disso, com a ajuda de uma companhia de colonização privada apoiada pelo governo, os carregadores brasileiros podiam ter uma vantagem competitiva em relação a esforços de recrutamento e transporte mais organizados de migrantes. O governo brasileiro também tinha a ganhar organizando e explorando estrategicamente transações relacionadas à colonização que tivessem sido realizadas por armadores brasileiros, como aquela que tirou um contrato de colonização da boca da Sociedade Australiana de Colonização em Hamburgo, em 1836. ${ }^{25}$ Mas esse tipo de sistematização continuaria existindo até o final da década de 1850, quando Pedro de Araújo Lima, Marquês de Olinda, empregou sua experiência institucional acumulada durante mais de 20 anos (desde que presidiu pela primeira vez a Sociedade Promotora) para encabeçar novos esforços de colonização mais regulamentados pelo governo.

A concorrência em torno da identificação, recrutamento, transporte e assentamento de mão de obra entre diferentes potências no Atlântico e além 
dele continuaria durante todo o século XIX e se estenderia até a era das migrações em massa. Entretanto, o aumento no volume e na frequência de migrações depois da década de 1870 foi concomitante a uma notória diminuição na diversidade de planos de colonização e suas justificativas ideológicas. No período inicial da República (1889-1930), a imigração era concebida quase exclusivamente como uma questão racial, um fato que assinala sua diferença para com a Regência e os primeiros anos do Segundo Império, quando a raça era somente um fator entre muitos outros levados em consideração em discussões sobre a colonização.

As muitas abordagens da colonização que políticos e comerciantes tentaram na década de 1830 eram um reflexo, por um lado, da multiplicidade de ideias sobre o assunto. Desde degredos administrados pelo governo ao recrutamento privado de migrantes, desde o esquema da Emigração Africana da Grã-Bretanha até tentativas de mercadores de escravos com "colonos africanos", essa foi uma época marcada por interações singulares entre administração governamental, oligarquias políticas e redes de empresas navais (Asiegbu, 1969; Mamigonian, 2009; Borucki, 2009). O resultado disso foi uma incrível diversidade de planos para movimentar tanto populações "livres" quanto forçadas pelo Atlântico - alguns bem-sucedidos, outros lucrativos, ainda que fraudulentos, e ao final dos quais, independentemente da percepção de seu sucesso ou fracasso, milhares de pessoas tinham sido sistematicamente transportadas para sociedades que não as suas originais. Entretanto, a variedade de esforços de colonização devia muito ao fato de que as oportunidades surgiam tão rapidamente quanto desapareciam. Acontecimentos internos e ultramarinos imprevistos ofereciam sucessivas aberturas para que planos de colonização fossem efetivados, e homens de Estado interessados em obter lucros ou polir suas credenciais - desde liberais como Vergueiro ou Holanda Cavalcanti até conservadores como Calmon e Araújo Lima - tirassem proveito deles. Nesse sentido, a colonização pode ajudar a lançar luz sobre o tumultuado período da Regência e suas turbulências políticas mostrando que havia noções sobre as quais existia um elevado consenso, embora houvesse profundas discrepâncias sobre como colocá-las em prática. Foi o acordo unânime sobre o valor prático da colonização que cimentou sua percepção como uma panaceia para os males de uma nação que se tornara independente pouco antes. Ironicamente, mesmo como uma solução para os desafios de um novo governo, a colonização dependia de fatores que estavam além do alcance soberano das elites políticas brasileiras, que, em todo caso, entendiam que ela seria mais bem aplicada por atores privados do que pelo próprio governo. 


\section{REFERÊNCIAS}

ALENCASTRO, Luiz Felipe. Prolétaires et Esclaves: Immigrés Portugais et Captifs Africains à Rio de Janeiro, 1850-1872. Cahiers du Centre de Recherches d'Études Ibériques et Ibéro-americaines de Rouen, v.4, p.119-156, 1984.

ALMEIDA, Miguel Calmon du Pin e. Memoria sobre o estabelecimento d'uma companhia de colonisação nesta Provincia. Bahia: Typ. do Diario de G. J. Bizerra, 1835.

ALVES, Jorge Fernandes. Os "brasileiros": emigração e retorno no Porto oitocentista. Tese (Doutorado) - Faculdade de Letras, Universidade do Porto. Porto, 1993.

ASIEGBU, Johnson U. J. Slavery and the Politics of Liberation, 1787-1861: A Study of Liberated African Emigration and British Anti-Slavery Policy. New York: Africana Publishing Corporation, 1969.

BALOGH, Brian. A Government Out of Sight: The Mystery of National Authority in Nineteenth-Century America. Cambridge: Cambridge University Press, 2009.

BORUCKI, Alex. The 'African Colonists' of Montevideo: New Light on the Illegal Slave Trade to Rio de Janeiro and the Río de la Plata (1830-42). Slavery and Abolition, v.30, n.3, p.427-444, 2009.

BROEZE, Frank. Private Enterprise and the Peopling of Australasia, 1831-50. The Economic History Review, v.35, n.2, p.235-253, 1982.

BROWNE, George. Política imigratória no Brasil Regência. Revista do IHGB, v.307, p.37-48, 1975.

COSTA, Emília Viotti da. Da monarquia à república: momentos decisivos. São Paulo: Unesp, 2010.

ESPINDOLA, Haruf Salem. A navegação do Rio Doce: 1800-1850. Navigator, v.3, n.5, p.50-72, 2007.

GIRON, Lorraine Slomp; BERGAMASCHI, Heloisa. Terra e homens: colônias e colonos no Brasil. Caxias do Sul, RS: Educs, 2004.

HAINES, Robin; SHLOMOWITZ, Ralph. Causes of Death of British Emigrants on Voyages to South Australia, 1848-1885. The Journal of the Society for the Social History of Medicine, v.16, n.2, p.193-208, 2003.

HAINES, Robin; SHLOMOWITZ, Ralph. Nineteenth-Century Government-Assisted and Total Immigration from the United Kingdom to Australia: Quinquennial Estimates by Colony. Journal of the Australian Population Association, v.8, n.1, p.50$61,1991$.

HITCHINS, Fred. The Colonial Land and Emigration Commission. Philadelphia: University of Pennsylvania Press, 1931.

HOLANDA, Sérgio Buarque de. Prefácio do tradutor. In: DAVATZ, Thomas. Memórias de um colono no Brasil (1850). São Paulo: Itatiaia, 1980. p.15-45.

LEÃO, Honório Hermeto Carneiro. Relatório [...] dos Negócios Estrangeiros. Rio de Janeiro: Typ. Imperial e Constitucional de J. Villeneuve, 1843.

LEITE, Joaquim da Costa. Portugal and Emigration, 1855-1914. Tese (Doutorado) Graduate School of Arts and Sciences, Columbia University. New York, 1994. 
MAIA, João Marcelo. Estado, território e imaginação espacial: o caso da Fundação Brasil Central. Rio de Janeiro: Ed. FGV, 2012.

MAMIGONIAN, Beatriz. In the Name of Freedom: Slave Trade Abolition, the Law and the Brazilian Branch of the African Emigration Scheme (Brazil-British West Indies, 1830s-1850s). Slavery and Abolition, v.30, n.1, p.41-66, 2009.

MANN, Michael. The Sources of Social Power. Vol. 2: The Rise of Classes and Nation-States, 1760-1914. Cambridge: Cambridge University Press, 2012.

NEEDELL, Jeffrey. The Party of Order: The Conservatives, the State and Slavery in the Brazilian Monarchy, 1831-1871. Stanford: Stanford University Press, 2006.

NODARI, Eunice. Persuadir para migrar: a atuação das companhias colonizadoras. Esboços, v.10, n.10, p.29-52, 2002.

NUNES, Rosana Barbosa. Portuguese Migration to Rio de Janeiro, 1822-1850. The Americas, v.57, n.1, p.37-61, 2000.

PARRON, Tâmis. A política da escravidão no Império do Brasil, 1926-1865. Rio de Janeiro: Civilização Brasileira, 2011.

RAMOS, Jair de Souza. O poder de domar o fraco: construção de autoridade e poder tutelar na política de povoamento do solo nacional. Niterói: Eduff, 2006.

REBELLO, José Silvestre. Memoria sobre a necessidade de se crearem sociedades entre os homens. Auxiliador da Indústria Nacional, v.1, n.11, p.2-16, 1833.

ROCHE, Jean. A colonização alemã e o Rio Grande do Sul. Trad. Emery Ruas. Porto Alegre: Globo, 1969.

SALLES, Ricardo. E o vale era escravo: Vassouras, século XIX: senhores e escravos no coração do Império. Rio de Janeiro: Civilização Brasileira, 2008.

SCHÖDER, Ferdinand. A imigração alemã para o sul do Brasil até 1859. [1931]. Trad. Martin Dreher. São Leopoldo, RS: Unisinos, 2003.

SILVA, João Manuel Pereira da. Segundo período do Reinado de dom Pedro I: narrativa histórica. Rio de Janeiro, Garnier, 1871.

SOUSA, Fernando de. A emigração portuguesa para o Brasil e as origens da Agência Abreu (1840). Porto: Cepese, 2009.

TRAMONTINI, Marcos Justo. A organização social dos imigrantes: a colônia de São Leopoldo na fase pioneira, 1824-1850. Porto Alegre: Unisinos, 2003.

VASCONCELLOS, Bernardo Pereira de. Relatório [...] dos Negócios do Império (1837). Rio de Janeiro: Typ. Nacional, 1838.

VERGUEIRO, Nicolau. Relatório do Ministério do Império do anno de 1832. Rio de Janeiro: Typ. Nacional, 1833.

\section{NOTAS}

${ }^{1}$ A pesquisa para este artigo foi possibilitada por uma bolsa do Nicholson Center for British Studies, uma verba para pesquisa de campo do Center for Latin American Studies, da Universidade de Chicago, e uma bolsa Fulbright-Hays DDRA (2013-2014). O autor agradece as 
gentis sugestões, durante a pesquisa para este artigo, de Emilio de Antuñano, Dain Borges, Eduardo Cavalcante, Suelem Demuner, Soraia Salles Dornelles, Carlos Gabriel Guimarães, Hendrik Kraay, Christopher Lesser, Karina Melo, José C. Moya, María Verónica Secreto, Mauricio Tenorio Trillo e pelos participantes da re:Work Summer Academy realizada pela Humboldt University na Unicamp em novembro de 2013.

${ }^{2}$ Eunice Nodari conta 13 companhias de colonização (uma estatal) de 1920 a 1940 em Santa Catarina (NODARI, 2002). Quanto à Expedição Roncador-Xingu, ver MAIA, 2012. Uso os termos poder "tutelar" e "infraestrutural" segundo a definição, respectivamente, de RAMOS, 2006, e MANN, 2012, p.59-63.

${ }^{3}$ Quanto a esforços anteriores de colonização e navegação na bacia do Rio Doce, cf. ESPINDOLA, 2007.

${ }^{4}$ Arquivo Nacional (AN), RJ, GIFI 4J-073, Decreto de 2 de dezembro de 1825; Biblioteca Nacional (BN), RJ, Seção de Manuscritos, I-32,09,019, "Projeto apresentado ao Senado para a utilização de mão de obra estrangeira e colonização do Brasil”.

${ }^{5}$ Anais do Senado (1827), t. 2. RJ, 1911, p.32-35; Anais do Senado (1828), t. 2. RJ, 1913, p.12.

${ }^{6}$ As revoltas de 1828 ocorreram entre 9 e 12 de junho. SILVA, 1871, p.286-291; 352-353.

${ }^{7}$ Ferdinand Schröder faz referência a discussões na Câmara dos Deputados de 1828 a 1830 para salientar como Pedro I perdeu apoio para seu esforço de colonização nesse período. Cf. SCHRÖDER, 2003 [1931], p.70-71.

${ }^{8} \mathrm{O}$ Universal, n. 460, 30 jun. 1830, resumiu a sessão de 11 de maio da Assembleia Nacional.

${ }^{9}$ Instituto Histórico e Geográfico Brasileiro (IHGB), Coleção Senador Nabuco, Lata 383, pasta 1, "Instruções secretas enviadas pelo Marquês de Abrantes ao Marquês de Santo Amaro em $21 / 4 / 1830 "$ ".

${ }^{10}$ A Comissão de Constituição e Diplomacia da Assembleia Nacional estudou em conjunto uma série de documentos, em junho de 1833, que pretendiam provar que o Duque de Bragança tinha a intenção de reinvadir o Brasil. Seus membros, que incluíam Miguel de Calmon, Ernesto Ferreira França e Pedro de Araújo Lima, tacharam despreocupadamente essas afirmações de possíveis, mas improváveis. Aurora Fluminense, n.787, 1 jul. 1833.

${ }^{11}$ Anais da Câmara dos Deputados (1826), t. 3. Rio de Janeiro: Typographia do Imperial Instituto Artístico, 1874, p.3-4. Curiosamente, quando um projeto de lei sobre agricultura e povoamento entrou em segunda discussão em 19 de julho de 1826, Vergueiro insistiu que se privilegiassem as companhias de navegação, e não proponentes individuais, o que estava em contradição com suas concepções, pois elas também eram companhias de colonização (cf. p.228). VERGUEIRO, 1833, p.24.

${ }^{12}$ Cf. ROCHE, 1969. v. I, p.99-100; BROWNE, 1975; GIRON; BERGAMASCHI, 2004. Quanto ao orçamento como meio de exercício da autoridade governamental, cf. BALOGH, 2009.

${ }^{13}$ Os gastos iniciais para "ensaios" com "colônias de degredados e vagabundos" determinados pela Lei $\mathrm{n}^{\circ} 58$ de 8 de outubro de 1833 foram fixados em 50 contos (R $\$ 50.000 \$ 000$ ), porém mais tarde foram reduzidos a 12. Não está inteiramente claro se essa mudança entrou em vigor no ano fiscal 1834-35 ou 1835-36. CLIB, 1833, ibidem. 
${ }^{14}$ BN, Seção de Obras Raras, 71, 6, 25. Os estatutos da Sociedade Promotora circularam amplamente através do Diário do Rio de Janeiro $(D R J)$, n. 11, 12 mar., e n. 12, 14 mar. 1836, bem como em CLIB (1836), ibidem, p.9-13. A Sociedade Colonisadora da Bahia, também conhecida como Companhia de Colonisação da Bahia, foi fundada em 1835. O Sete d'Abril, n.299, 1 dez. 1835, reproduziu a "Acta da Installação".

${ }^{15}$ Diário do Rio de Janeiro, n.23, 27 fev. 1836; n.94, 26 abr. 1839. AN, Agricultura, IA6 160.

${ }^{16}$ Decreto de 7 de janeiro; Decreto de 9 de agosto, CLIB (1836), ibidem, p.5-7; 84-88.

${ }^{17}$ Os requerimentos da Câmara Municipal de Ouro Preto e do Legislativo de Minas Gerais ao Tribunal em nome da Companhia do Rio Doce se encontram em BN, Seção de Manuscritos, Coleção Minas Gerais, II-36, 07,002. Quanto à nomeação de Sturz, cf. LEÃO, 1843. Quanto a listas dos despachos de livros por parte de Sturz dos quais se trata mais adiante, cf. IHGB, Coleção Instituto Histórico, Lata 139, pasta 86; Lata 141, doc. 5.

${ }^{18}$ AN, GIFI 5B-478.

${ }^{19}$ A “colonização sistemática" foi também uma reação a um processo emigratório que tinha oscilado entre tutela direta por parte do governo e práticas de livre mercado. Cf. BROEZE, 1982; HITCHINS, 1931.

${ }^{20}$ ALVES, 1993, p.134; ALENCASTRO, 1984; VASCONCELLOS, 1838, anexo no 7. Esse número não reflete o total da imigração portuguesa para o Brasil e nem mesmo para o Rio de Janeiro, já que a Sociedade só aceitava imigrantes para os quais tinha acertos prévios. O número também não contém a migração clandestina maciça dos Açores que foi amplamente relatada pela imprensa, mas não consta em registros de passaportes e outros documentos oficiais. Uma investigação preliminar da Movimentação dos Portugueses no AN (www.an. gov.br/baseluso/) sugere que, no período 1828-1842, pelo menos cerca de 3.600 açorianos entraram oficialmente no porto do Rio de Janeiro, mas isso nada diz a respeito da frequência de sua entrada. Outro desafio na tentativa de determinar o número de chegadas de açorianos ao Rio é que não há registro dos homens recrutados para trabalhar em Portugal continental, que poderiam, teoricamente, migrar mais tarde para o Brasil via Lisboa ou Porto, aparecendo, assim, como chegadas desses portos e não dos Açores.

${ }^{21}$ Arquivo Nacional Torre do Tombo, Lisboa, Min. do Reino, Maço 2039; DRJ, n 102, 6 maio 1839.

${ }^{22}$ SOUSA, 2009, p.29; Decreto de 14 de maio de 1838; Portaria de 2 de junho de 1838; Portaria de 13 de julho de 1838. In: Boletim do Conselho Ultramarino, 1834-1850, Imprensa Nacional: Lisboa, 1867, p.41-45, 49-50, 51.

${ }^{23}$ HAINES; SHLOMOWITZ, 1991; 2003; National Archives, London (Kew), F.O. 13/163, ff. 73-89, 95; F.O. 13/173, ff. 36-53; Admiralty Records (ADM), 101/60/3.

${ }^{24}$ DRJ, no 3, 4 dez. 1837; The Sydney Gazette \& New South Wales Advertiser, n. 4036, 26 jun. 1838.

${ }^{25}$ Colonial Times (Hobart), 24 jan. 1837.

Artigo recebido em 7 de julho de 2014. Aprovado em 15 de outubro de 2014. 